Annals of the Rheumatic Diseases, 1988; 47, 337-339

Case report

\title{
Sarcoidosis presenting as antinuclear antibody positive glomerulonephritis
}

\author{
MARIA CRISTINA SOTO-AGUILAR AND DENNIS W BOULWARE \\ From the Section of Rheumatology, Tulane University Medical Center, New Orleans, USA
}

SUMMARY A 43 year old woman who initially presented with the nephrotic syndrome, glomerulonephritis, and antinuclear antibodies (ANAs) was given the diagnosis of systemic lupus erythematosus (SLE). One year later the patient developed progressive subcutaneous nodules on her forearms, with histopathology of non-caseating granulomas. Further evaluation of the patient showed mediastinal lymphadenopathy and interstitial lung disease with numerous granulomas, establishing the diagnosis of sarcoidosis. The presence of autoimmune antibodies and glomerulonephritis has been reported in sarcoidosis, but this case is believed to be the first in which both glomerulonephritis and ANAs are present in a sarcoid patient.

The aetiology of sarcoidosis is unknown, but many observations tend to link this disease with the autoimmune connective tissue diseases. ${ }^{1}$

The clinical manifestations of sarcoidosis are varied depending on the organ tissue or system involved, but the most significant and life threatening complications relate to cardiac involvement, progressive pulmonary disease, ocular, central nervous system, renal, hepatic and endocrine involvement, hypersplenism with cytopenias, and disfiguring skin lesions. ${ }^{2}$

Glomerular disease is one of the three major categories of renal manifestations of sarcoidosis ${ }^{3}$ and resembles the lesions observed in systemic lupus erythematosus (SLE). We describe a patient with membranous glomerulonephritis and antinuclear antibodies (ANAs) for one year before the onset of granuloma formation.

\section{Case report}

A 43 year old black woman, previously in good health, presented in April 1985 with anasarca. Her serum albumin was $17.5 \mathrm{~g} / \mathrm{l}$, serum creatinine 230

Accepted for publication 17 July 1987.

Correspondence to Dr Dennis W Boulware. Section of Rheumatology, Tulane University Medical Center, 1430 Tulane Avenuc, New Orleans, LA 70112, USA. $\mu \mathrm{mol} / \mathrm{l}$, and a 24 hour urine collection showed $9 \mathrm{~g}$ proteinuria. A microcytic normochromic anaemia with haemoglobin $100 \mathrm{~g} / \mathrm{l}$ was found, with a low serum iron and low total iron binding capacity. Serology showed normal C3 and C4 levels, positive ANA test with speckled pattern at a titre of $1 / 320$, and specific ANA tests were positive for only antiRNP. Antibodies to RNP, Sm, SS-A, and SS-B antigens were tested by agarose gel double diffusion immunoprecipitation. Anti-double-stranded DNA was tested by Crithidia immunofluoresence. Percutaneous renal biopsy showed a crescentic and membranous glomerulonephritis with focal and segmental sclerosis and strong immunofluorescence for IgG within the capillary loops. Apart from generalised oedema the patient had no other complaints and she appeared to have no other system involvement.

Treatment was started with $40-60 \mathrm{mg}$ prednisone a day. Her proteinuria decreased, but renal function gradually deteriorated and she developed mild to moderate hypertension. Because of weight gain and acne the patient discontinued her prednisone therapy in April 1986. In late June she noted the gradual appearance of subcutaneous indurated plaques and nodules on both forearms, which increased in number, size, and extension along the extensor surface, associated with progressive super- 
ficial erythema and warmth. Prednisone was resumed at a daily dose of $40 \mathrm{mg}$, with slow improvement in the skin lesions. Two weeks later assessment showed a middle aged woman in no distress, afebrile, with a blood pressure of $140 / 100$ $\mathrm{mmHg}$. The mucous membranes were intact, there was no cervical, axillary, or inguinal lymphadenopathy, and the cardiovascular, pulmonary, abdominal, and neurological systems were unremarkable. On the right forearm she had a firm, tender, subcutaneous, indurated plaque measuring $5 \times 20 \mathrm{~cm}$ along the extensor surface of the arm, with mild diffuse oedema. On the left forearm there were multiple tender, $1-2 \mathrm{~cm}$, subcutaneous nodules along the extensor surface. A subcutaneous nodule was present on the right knee. Her haemoglobin was $99 \mathrm{~g} / \mathrm{l}$, erythrocyte sedimentation rate (Westergren) $50 \mathrm{~mm} / \mathrm{h}$, white blood cell count $5 \times 10^{9} / \mathrm{l}$ with normal differential, normal prothrombin time and partial thromboplastin time. Urea nitrogen was $17.4 \mathrm{mmol} / \mathrm{l}$, creatinine $371 \mu \mathrm{mol} / \mathrm{l}$, uric acid $0.7 \mathrm{mmol} / \mathrm{l}$, calcium $2.7 \mathrm{mmol} / \mathrm{l}$, phosphorus $1.5 \mathrm{mmol} / \mathrm{l}$, and liver function tests were normal. Urinary protein excretion was $1.23 \mathrm{~g}$ in 24 hours, the urinary sediment was unremarkable, and the creatinine clearance was $14 \mathrm{ml} / \mathrm{min}$. Rheumatoid factor and Venereal Disease Research Laboratory tests were negative, complement levels normal, and an ANA test was positive with a speckled pattern at 1/256 with negative specific ANAs, including RNP. The serum protein electrophoresis showed a polyclonal gammopathy and albumin $37 \mathrm{~g} / \mathrm{l}$. Her IgG level was $20 \cdot 3 \mathrm{~g} / 1$ (normal 8-18), IgA $3 \cdot 3 \mathrm{~g} / \mathrm{l}$ (normal $0.9-4.5$ ), and IgM $0.87 \mathrm{~g} / 1$ (normal $0.7-2 \cdot 8$ ).

A deep skin biopsy of one of the left forearm nodules showed non-caseating granulomas affecting the dermis and subcutaneous tissue, with no signs of vasculitis or necrosis. Special stains were negative for micro-organisms, and immunofluorescent staining was also negative. The patient's chest radiograph, initially judged to be unremarkable, was reviewed and found to have increased interstitial markings and prominent hilar areas suggestive of lymphadenopathy, which were eventually confirmed by a computed tomographic scan of the chest. Pulmonary function tests, including diffusion capacity, were within normal limits. Transbronchial biopsy showed the presence of multiple non-caseating granulomas. Acid fast bacilli and fungal stains were negative, and cultures were negative after three months. The angiotensin converting enzyme level was $34 \mathrm{IU} / \mathrm{ml}$ (normal 10-30 IU $/ \mathrm{ml}$ ).

The patient was discharged while continuing to receive prednisone $40 \mathrm{mg}$ daily. The progressive worsening of the renal function was attributed to progression of fibrosis and loss of glomerular tissue.

\section{Discussion}

The reported prevalence of histopathological rena金 involvement in patients with sarcoidosis ranges frorto $4 \cdot 3 \%$ to $40 \%,{ }^{34}$ though significant functiona亞 impairment is less frequently observed. Sarcoidosis, may involve the kidneys in several ways, of which calcium nephropathy and interstitial granulomatous infiltration are the most common. Other manis festations are granulomatous arteritis and sarcoid $\vec{P}$ glomerulopathy.

Nephrotic syndrome is frequently present in patients with sarcoid glomerulopathy and the histo logical findings resemble the various primary forms of glomerulonephritis (i.e., membranous, endo-capillary proliferative, crescentic proliferative, and end stage chronic glomerulonephritis). Of these membranous glomerulonephritis seems to have of higher prevalence among patients with sarcoid glomerulopathy than among those with idiopathic glomerular disease. ${ }^{5}$ Immunofluorescent studies are usually positive, with patterns varying from granular or linear deposition of $\mathrm{IgG}$ alone to IgG in association with $\operatorname{IgA}, \operatorname{IgM}$, and $\mathrm{C}^{3}{ }^{6}$ outlining the capillary walls. Similarly, electron microscoplo frequently shows electron dense deposits on the epithelial side of the basement membrane.

Sarcoidosis is a disorder characterised by multio system involvement, non-caseating granulomas, an sterile cultures. The mechanisms initiating the inflammatory reaction are unknown and the natura $\$$ history of the disease is uncertain. The clinicap manifestations vary and may mimic other diseases? Owing to the histopathological findings in the renat biopsy specimen and the presence of a positive ANA test, our patient was initially considered to have lupus nephritis and was treated with cortico steroids for several months. Granuloma formatio did not present clinically at the onset of her illness? Two months after the patient had discontinued of one year course of prednisone, subcutaneous nodules developed on the extensor surface of bot forearms, accompanied by a diffuse local inflamn mation. When prednisone therapy was resumed the lesions responded in a period of a few weeks. Skirô biopsy provided the essential clue to the diagnosis which was confirmed by transbronchial biopsyo despite the normal pulmonary function tests.

It is considered that granulomas form around relatively insoluble antigen, ${ }^{7}$ either by a specifice immunological mechanism involving specificallyo sensitised $T$ cells and macrophages, or by a non우 immunological or non-specific reaction. Sarcoidosi has cellular and humoral immune abnormalities, ${ }^{18} \mathrm{\%}$ most of which are suggestive of a defect in the suppressor regulatory system: hyperactivity of the 
immune system with hypergammaglobulinaemia; defective cell mediated immune function; loss of tolerance to self antigens (appearance of autoantibodies, antilymphocyte antibodies, and manifestations of cell mediated hypersensitivity); depression of antibody dependent, cell mediated cytotoxicity; and an increased number of circulating monocytes. In this respect sarcoidosis has immunological features in common with those of SLE. Cases of progressive systemic sclerosis, ${ }^{1}$ autoimmune thrombocytopenic purpura, ${ }^{10}$ and SLE ${ }^{11}$ have been reported to coexist with sarcoidosis. In these cases sarcoidosis preceded or followed the onset of the connective tissue disease. Our patient's case did not meet sufficient criteria for the American Rheumatism Association classification of SLE as apart from her renal disease and a positive ANA test there was no other system involvement suggestive of lupus. Instead, her general picture could well be explained by sarcoidosis.

Veien et al in a series of 50 patients with sarcoidosis reported more than $30 \%$ positivity of organ-non-specific antinuclear antibodies, though anti-DNA antibodies were not demonstrated. ${ }^{7}$ Oreskes and Siltzbach observed the presence of rheumatoid factor (RF) in $44 \%$ of patients with active sarcoidosis, in contrast with patients in the inactive phase of the disease, who had no rheumatoid factor activity. ${ }^{12}$ Most of the patients with a positive $\mathrm{RF}$ test were women with a median RF titre of $1 / 160$. A fall in the level of autoantibodies has been observed after treatment with steroids and in inactive sarcoidosis. A fall in autoantibody titre is considered a good prognostic sign in sarcoidosis. ${ }^{13}$

This case represents an unusual presentation of sarcoidosis, with initial clinical manifestations and humoral autoimmune activity simulating SLE. Glomerulonephritis associated with sarcoidosis and sarcoidosis associated with the presence of autoantibodies have been reported elsewhere, but this is the first report in which all three components are present in the same individual. It is possible that sarcoidosis and autoimmune disorders share common immunopathogenic mechanisms, and this disease may eventually be incorporated into the connective tissue diseases. Finally, renal function and serology should be followed up in patients with sarcoidosis.

\section{References}

1 Wiesenhutter C W. Sharma G P. Is sarcoidosis an autoimmune disease?: report of four cases and review of the literature. Semin Arthritis Rheum 1979; 9: $124-44$.

2 Albelda S M. Daniele R P. Sarcoidosis. In: Lichtenstein L. Fauci A S, eds. Current therapy in allergy, immunology and rheumatology. Toronto: BC Decker, Inc. 1985-6: 120-5.

3 Tisher C C, McCoy R C. The kidney in sarcoidosis. In: Hamburger J, Crosnier J, Grunfeld J P. eds. Nephrology. New York: Wiley, 1979: 655-63.

4 Muther R S. McCarron D A. Bennett W M. Renal manifestations in sarcoidosis. Arch Intern Med 1981: 141: 643-5.

5 Taylor R G. Fisher C. Hoffbrand B I. Sarcoidosis and membranous glomerulonephritis: a significant association. $\mathrm{Br} \mathrm{Med} J$ 1982; 284: 1297-8.

6 Goldszer R C. Galvanek E G, Lazarus J M. Glomerulonephritis in a patient with sarcoidosis: report of a case and review of the literature. Arch Pathol Lab Med 1981; 105: 478-81.

7 Veien N K. Hardt F, Bendixen G, et al. Humoral and cellular immunity in sarcoidosis. Acta Med Scand 1978; 203: 321-6.

8 de la Figuera M, Marquet R, Vilardell M. Ribera E, Villar M. Autoimmunidad humoral en una paciente con sarcoidosis. Med Clin (Barc) 1983; 81: 320.

9 de la Figuera M. Sanjuas C. Vilardell M, Morera J, Marquet R, del Mar Villar M. Anticuerpos antinucleares en la sarcoidosis. Med Clin (Barc) 1983: 81: 878-9.

10 Lawrence H J. Greenberg B R. Autoimmune thrombocytopenia in sarcoidosis. Am $J$ Med 1985; 79: 761-4.

11 Neddleman S W. Silber R A, von Brecht J H, Goeken J A. Systemic lupus erythematosus complicated by disseminated sarcoidosis. Am J Clin Pathol 1982; 78: 105-7.

12 Oreskes I, Siltzbach L E. Changes in rheumatoid factor activity during the course of sarcoidosis. Am J Med 1968; 44: 60-7.

13 Olenchock S A. Marx J J. Mull J C, et al. Immunology of clinically inactive sarcoidosis: serum factors. Ann Allergy 1981; 47: 28-31. 